\title{
Evaluation of Organochlorine Pesticide Residues in Fish and Water from Lake Geriyo in Yola North Local Government Area of Adamawa State, Nigeria
}

\author{
*Priscilla Alexander ${ }^{1} \quad$ Mohammed Minkailu $^{1} \quad$ Ismaila Yada Sudi $^{2}$ \\ 1.Department of Chemistry, Adamawa State University, P.M.B. 25, Mubi, Nigeria \\ 2.Department of Biochemistry, Adamawa State University, P.M.B. 25, Mubi, Nigeria
}

\begin{abstract}
Pesticides usage in agricultural fields to control pests is extremely toxic to non-target organisms like fish and affects fish health through deterioration of metabolism, and sometimes leading to death. The present study was carried out to determine the level of organochlorine (OC) pesticide residues in, water and fish (Catfish and Tilapia) from Lake Geriyo, in Adamawa State, Nigeria, in order to find out the extent of pesticide contamination and accumulation in the lake. Soxhlet extraction process was used for the extraction of fish using a mixture of hexane and acetone, while water sample was extracted using dichloromethane liquid- liquid extraction method. The extracts were cleaned-up and analyzed using a gas chromatograph mass spectrometer (GC-MS). The result shows that organochlorine pesticides residues such as endrin, aldrin, dieldrin, heptachlor were detected in the water and the fish samples of the study area. Dieldrin was the predominant residue in all the fish samples analysed, at the concentration range of $0.36 \mathrm{mg} / \mathrm{kg}$ to $0.57 \mathrm{mg} / \mathrm{kg}$ and $0.051 \mathrm{mg} / \mathrm{kg}$ to $0.047 \mathrm{mg} / \mathrm{kg}$ in Tilapia and catfish respectively, while Lindane was of higher concentration in water samples, $(0.33 \mathrm{mg} / \mathrm{L})$ in point $\mathrm{p} 1$ upstream and $0.27 \mathrm{mg} / \mathrm{L}$ in point p2 downstream. The lowest levels of OC pesticides were related to Endrin, Aldrin and Heptachlor in which Endrin and Heptachor were not found in water samples. The result of the investigation shows that matured fish contain higher concentration of the OC pesticide residues than the immature fish. Dieldrin and Lindane were found to be the predominant pesticide residues in all the analysed water and fish samples. Therefore the result indicates that Lake Gariyo is contaminated by pesticide from the nearby vegetable gardens which affects the water quality and non target organisms like fishes thereof.
\end{abstract}

Keywords: Organochlorine, Pesticides, Lake Geriyo, Adamawa State, Fish and Water

DOI: $10.7176 / \mathrm{CMR} / 11-2-03$

\section{Introduction}

Pesticides residue is present everywhere in the environment and these may pose health threat to both plants and animals due to their persistent, bio-accumulation ability, potential toxicity and bio-concentrate in organism (Darko et al., 2008). Many of these OC pesticides when used properly are of great benefits to humans and the environment, these pesticides are widely used in agriculture and other sectors especially as insecticide and some of these pesticides are used to controlled mosquitoes (Farshid et al., 2012). However, their metabolites have been involved in a wide range of adverse human and environmental effects such as reproduction and birth defects, immune system dysfunction, endocrine disruptions and cancer (Adeyemi et al., 2008).

Organochlorine pesticides (OCPs) are among the major types of pesticides notorious for their high toxicity (El-Mekkawi, 2009). Biological samples (fish, aquatic and terrestrial mammals and birds) as well as soils and sediments have higher concentrations of most OCPs than water or air, making them more suitable for routine monitoring and more relevant in the context of exposure of humans and wildlife (Wang et al., 2010).

Fish accumulates some organic chemicals particularly OCPs in its fatty tissues due to its inability to metabolize them in the food they eat and from the intake of particulates in water and sediment unto which these chemicals have been adsorbed (Guo et al., 2008). The area of accumulation of pesticides within fish varies with the rout of uptake. The gills are directly in contact with water; therefore, the amount of pesticides in gills reflects their concentration in water where the fish live (Izelyamu et al., 2007). The average concentration of these OCPs increases dramatically across a food chain. The bioaccumulation of organochlorines in fish and other animals is the reason why most of the human daily intake of such chemicals comes from our food supply rather than from water (Imo et al., 2007). Their ability to be use as bio-monitors is therefore important in the assessment of bioaccumulation and bio-magnifications of impurity within the ecosystem (Akan and Unyimadu, 2013).

The data on pesticides residue especially in Nigeria are very scarce therefore, there is need to investigate the levels of pesticides residues in this area, data that will be generated from this investigation will serve as a reference material and also will be used to advise the populace on the use of pesticides (Shinggu et al., 2015).This work, therefore, seeks to provide base line information on levels of OCPs including DDT, DDE, lindane, endosulfan, heptachlor and chlordane in fish and surface water of Lake Geriyo, this will assists in a scientific assessment of the impact of pesticides on public health, agriculture and the environment in Adamawa State, Nigeria. 


\section{Materials and Methods}

\subsection{Description of the Study Area}

Water and fish samples were collected from Lake Geriyo. The Lake is situated in Yola North Local Government Area of Adamawa State and located on latitude $09^{0} 18^{\prime} 11^{\prime \prime} \mathrm{N}$ and longitude $12^{0} 25^{\prime} 36^{\prime}$ ' E. The lake is mostly used for irrigation, mostly for vegetable farming and for fishing business, for the fishermen. However, the lake also serves as a source of drinking water for the large cattle farmers, providing water for their cattle.

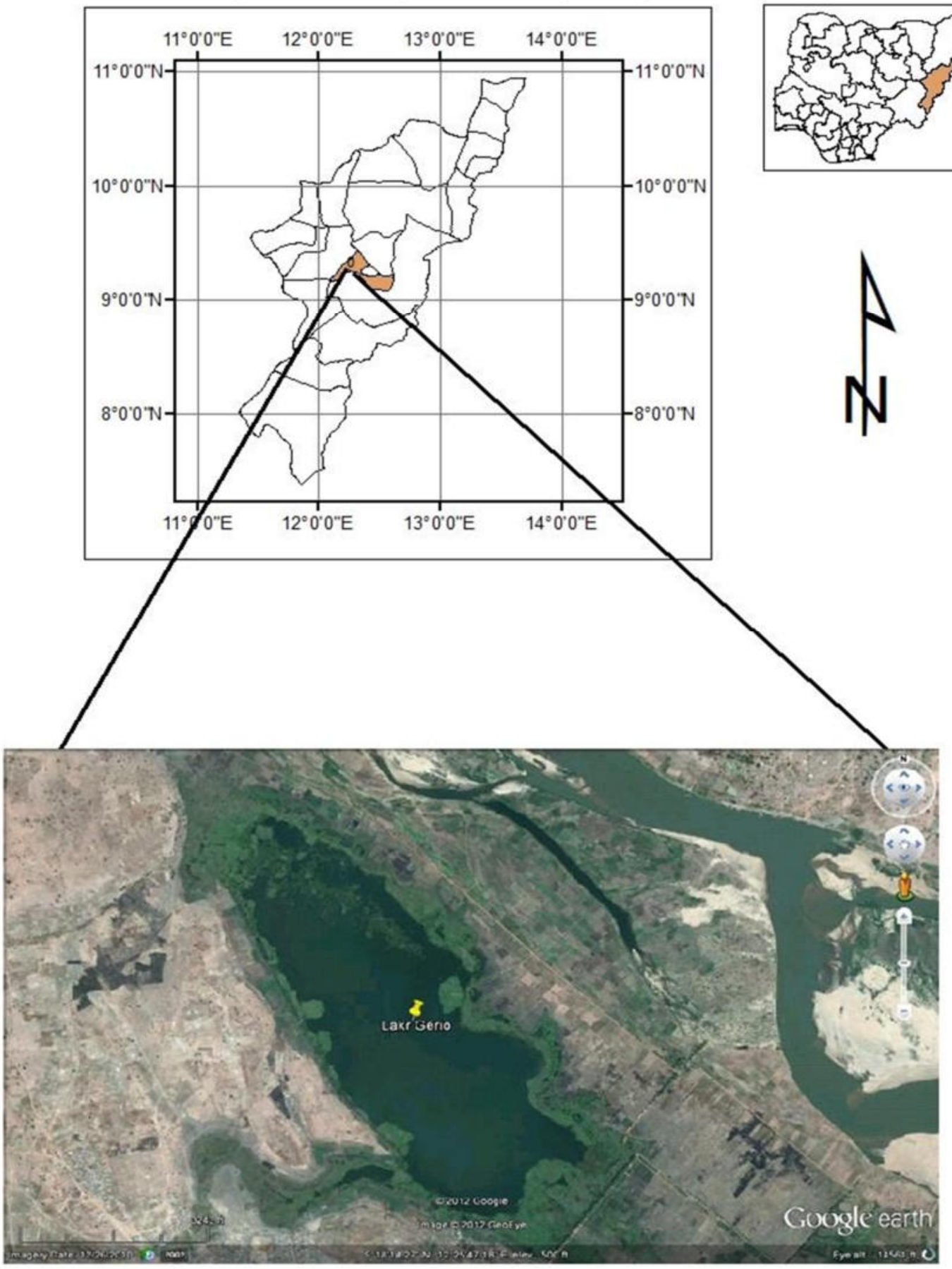

Figure 1. Map of Adamawa State showing the location of lake Geriyo (Google earth) 


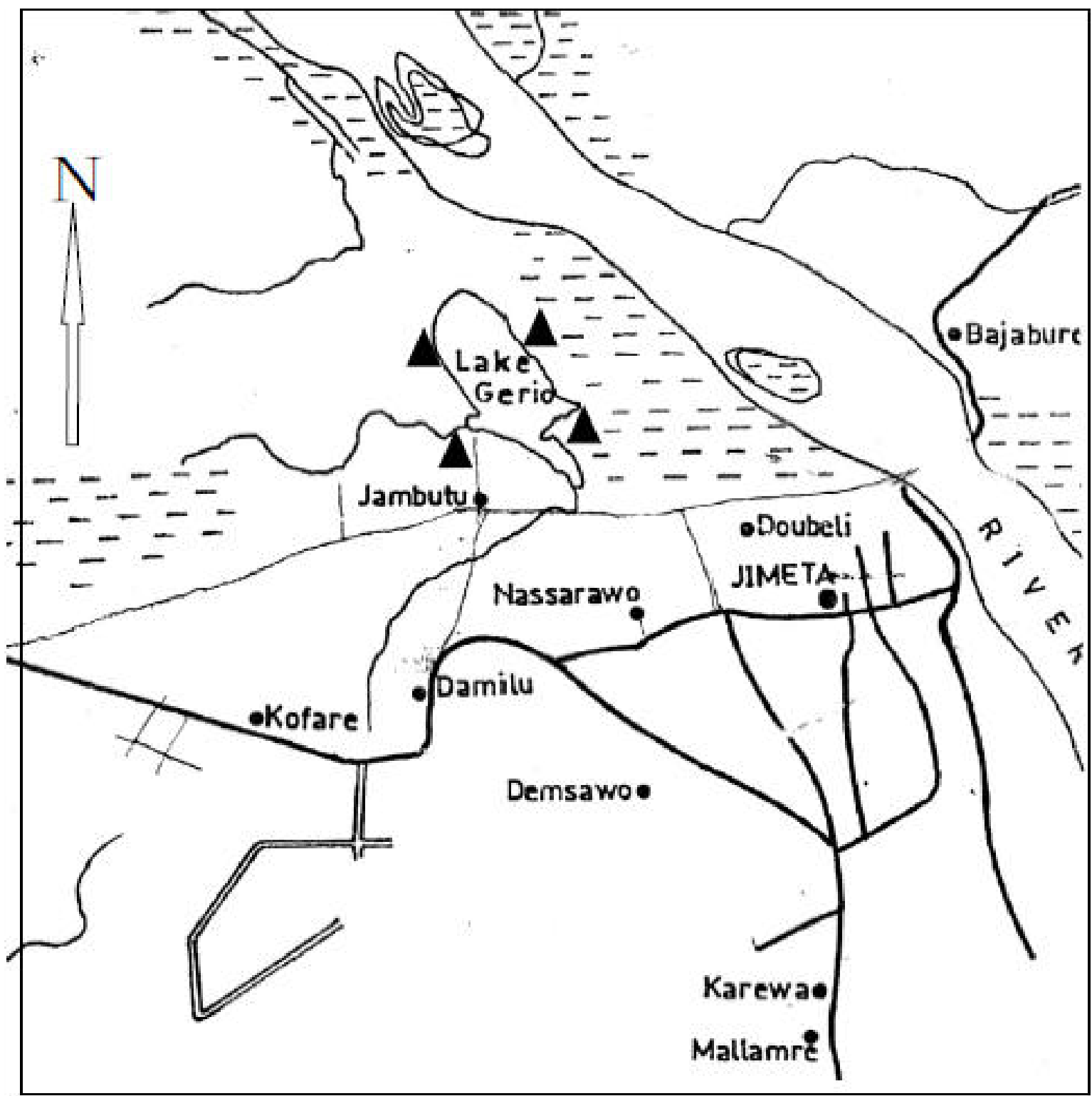

\section{Key;}

\section{Road}

\section{Sampling Sites $\boldsymbol{\Lambda}$}

Figure 2: Map of Yola North Showing the Study Area

\subsection{Experimental}

Analytical reagent (AnalaR) grade chemicals and distilled water were used throughout the study. All the equipment used are of laboratory standard, and all the glassware and plastic containers used in this work were washed with detergent solution followed by $20 \%(\mathrm{v} / \mathrm{v})$ nitric acid and then rinsed with tap water and distilled water.

\subsection{Sample Collection.}

2 Liters each of water samples were collected using standard water sampling procedure. Grab sampling techniques as describe by (Akinnawo, 2016) was used for the collection of water samples. Fish and water samples were collected from two different locations, in the month of March, 2018. The $\mathrm{pH}$ and temperature of the water samples 
were measured immediately at the point of collection and the water samples were preserved by refrigeration at $4^{0} \mathrm{C}$. Four different species of fish were collected, two species of Catfish (Clarias $s p$ ) and two species of Tilapia (Tilapia $s p$ ). These fishes were purchased directly from commercial fishermen at the study area. The fish samples were stored in thermo insulator box and transported to the laboratory. At the laboratory, the fish samples were washed several times with distilled water to clean from sediments and other entangled materials. The fish samples were identified for authentication by specialist from the Department of Fisheries and Aquaculture, Adamawa State University, Mubi. The fish species are label with unique identification codes and then wrapped in aluminum foil. The wrapped fish samples were placed in a polyethylene bags and kept in the freezer prior to sample preparation and analysis.

\subsection{Sample Extraction Procedures.}

Liquid-liquid extraction of organochlorine pesticide residues in water samples was carried out, using Method 3510 as described by USEPA 2007. Liquid- liquid extraction was used to extract organochlorine pesticide residues from the water samples. $50 \mathrm{~mL}$ of dichloromethane (DCM) was introduced into a separating funnel containing $100 \mathrm{~mL}$ of the water sample and shaken vigorously for 5 minutes. The sample was allowed to settle for 30 minutes to facilitate effective separation of the organic and aqueous phases. After separation, the organic layer was filtered into a $250 \mathrm{~mL}$ volumetric flask through anhydrous sodium sulphate $\left(\mathrm{Na}_{2} \mathrm{SO}_{4}\right)$ that has been prewashed with DCM. The extraction was repeated twice using $50 \mathrm{~mL}$ of dichloromethane (DCM). The extracts were later combined to make a whole. The extracts were concentrated to $5 \mathrm{~mL}$ using a rotary evaporator at a temperature of $45^{\circ} \mathrm{C}$, during concentration the solvent is exchanged with $\mathrm{n}$-hexane. The level of organochlorine pesticide residues in the water samples was determined using gas chromatography coupled with a mass spectrometer (GC-MS) (Akinnawo, 2016).

\subsection{Extraction of OC Pesticides in Fish Sample}

The muscle tissues of the fish sample were grounded in a blender to obtain homogenous composite. Organochlorine (OC) residues in fish samples were extracted using a Soxlet extractor. $10 \mathrm{~g}$ sample was placed into a beaker containing $50 \mathrm{~g}$ anhydrous sodium sulfate and mixed thoroughly. The sample mixture was transferred to an extraction thimble and placed in a Soxhlet extractor. The mixture was extracted with $150 \mathrm{ml}$ of acetone: $\mathrm{n}$ hexane $(20: 80 \mathrm{v} / \mathrm{v})$ at $50^{\circ} \mathrm{C}$ for $4 \mathrm{~h}$. The extract was filtered, concentrated to $1 \mathrm{ml}$ using a vacuum rotary evaporator. Each of the raw extracts was then dissolved in $10 \mathrm{ml}$ hexane and passed through pre-conditioned octadecyl C-18 columns at a rate of $2 \mathrm{ml}$ min G1 to clean up. The column was washed with $1 \mathrm{ml}, 30 \%$ methanol followed by $1 \mathrm{ml}$ ultrapure water and was allowed to dry. The sample (analyte) which was trapped in the column was eluted 5 times with $0.5 \mathrm{ml}$ aliquots of hexane to recover the pesticide residues. Hexane in the sample was then being allowed to evaporate off leaving the residue alone in the vial. Dried sample was dissolved in $1 \mathrm{ml}$ portion of hexane, mixed thoroughly with a whirl mixer and then transferred to auto sampler vials ready for gas chromatography (Farshid et al., 2012).

\subsection{Sample Clean up.}

The extract resulting from the phase separation of sample extract preparation supernatant, was transferred to a vial tube of graphite carbon, each sample was shaken for a minute then centrifuged for $4-5 \mathrm{mins}$ at $3500 \mathrm{rfc}$. After the centrifugation stop, the supernatant was ready for GC-MS analysis.

\subsection{Statistical Analysis}

A statistical analysis was carried out by the analysis of variance (ANOVA) using Duncan test. The results were presented as mean and standard deviation of three determinations.

\section{Results and Discussion}

Lake Geriyo is surrounded by farm lands which are use for irrigation farming. Large amount of chemicals such as pesticides and fertilizers were constantly applied by the farmers, which can enter the lake through leaching, water runoff, and subterranean canals. The lake is also used as a place where waste water and garbage are poured into by the inhabitants; all these factors may lead to the contamination of the lake. The results of the investigation from the study area were presented in tables 1,2 and 3 which are related to the concentration of OCPs in water and fish samples, respectively. 
Table 1: Mean concentration of organochlorine pesticide residues in water samples from point $P_{1}$ (upstream) and $\mathrm{P}_{2}$.(downstream) (Mg/L)

\begin{tabular}{llllll}
\hline POPs & LOQ & \multicolumn{1}{c}{ Point $\mathbf{P}_{\mathbf{1}}$} & \multicolumn{1}{c}{ Point $\mathbf{P}_{\mathbf{2}}$} & EU MRL & FEPA MRL \\
\hline Aldrin & 0.001 & $0.02 \pm 0.003$ & $0.017 \pm 0.001$ & 0.0001 & 0.01 \\
Endrin & 0.0028 & trace & trace & 0.0001 & 0.01 \\
Dieldrin & 0.0027 & $0.25 \pm 0.002$ & $0.31 \pm 0.004$ & 0.0001 & 0.01 \\
Heptachlor & 0.0050 & $0.028 \pm 0.002$ & trace & 0.0001 & 0.01 \\
Lindane & 0.0027 & $0.33 \pm 0.001$ & $0.27 \pm 0.007$ & 0.0001 & 0.01 \\
\hline
\end{tabular}

LOQ= limit of quantification, EU MRLs= European Union Maximum residue limits

ND $=$ Not detected, FEPA = Federal Environmental Protection Agency

Traces = concentrations below LOQ; cannot be quantitatively determined.

The results of the mean concentrations of some organochlorines pesticide residues such as Aldrin, Endrin, dieldrin, heptachlor and lindane in water samples from Lake Gereyo, obtained at two points; $\mathrm{P}_{1}$ (upstream) and $\mathrm{P}_{2}$ (downstream) are presented in table 1. From the results of the OCPs investigated in water samples, it was found that OCPs were detected in the water samples, except endrin and heptachlor which were not detected. The concentration of aldrin ranged from $0.02 \pm 0.003 \mathrm{mg} / \mathrm{L}$ in upstream and $0.017 \pm 0.001 \mathrm{mg} / \mathrm{L}$ downstream; Dieldrin ranged from $0.25 \pm 0.002 \mathrm{mg} / \mathrm{L}$ in upstream and $0.31 \pm 0.004 \mathrm{mg} / \mathrm{L}$ in the downstream. Lindane has the highest concentration of $0.33 \pm 0.001 \mathrm{mg} / \mathrm{L}$ in the upstream and $0.27 \pm 0.007 \mathrm{mg} / \mathrm{L}$ in the downstream. The result shows that the water samples were contaminated to some degree with Lindane. The level of contamination of these OCPs in the water samples were in the following order Lindane $>$ Dieldrin $>$ Aldrin $>$ Heptachlor. The results of this investigation are in accordance with the results obtained by Shinggu et al., 2015, in which the values of these OCPs were slightly higher than the present study. This shows that the concentrations of these pesticides decreases with time in the lake, this may be attributed to the reduced usage of these organochlorine pesticides by farmers, since OCPs have been banned for decades in Nigeria, this may also contributed to the absence of some of these pesticides in water samples. However, from the investigation it was observed that the level of all the OCPs detected in the analysed water samples exceeded the EU and FEPA Maximum residue limits for protection of aquatic animals and drinking. Organochlorine pesticides are hydrophobic and have little solubility in water. They have rather high affinity for particulate matter and may bind to lake sediments through sedimentation or bind to other solid aquatic life (Akan and Unylmadu, 2013).

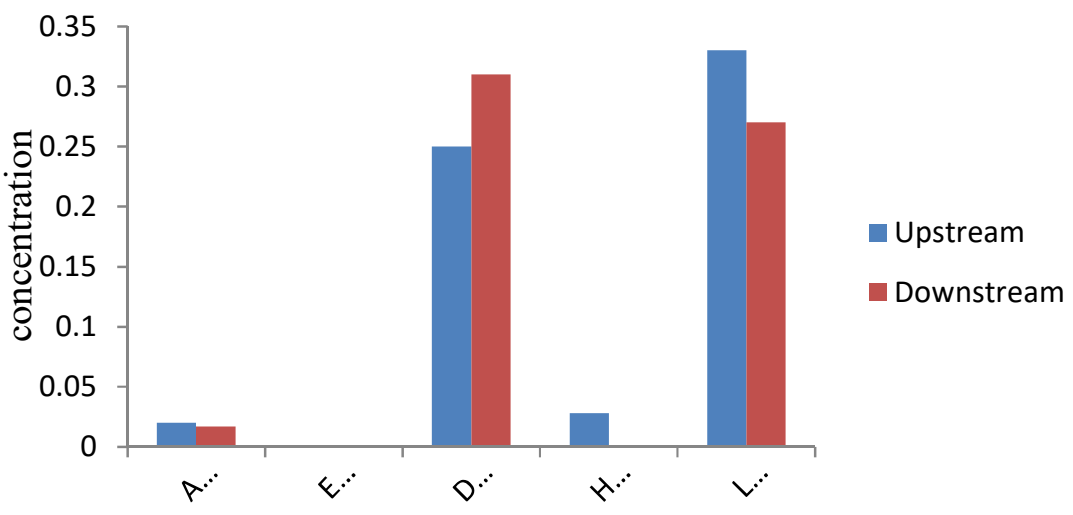

Fig 1: Comparison of organochlorine pesticide residues between upstream and downstream of the lake. $\mathrm{A}=$ Aldrin, $\mathrm{E}=$ Eldrin, $\mathrm{D}=$ Dieldrin, $\mathrm{H}=$ Heptachlor, and $\mathrm{L}=$ Lindane

Figure 1 shows that the most predominant OCPs in water samples are Dieldrin and Lindane; with dieldrin having higher concentration in the downstream while lindane is having higher concentration in the upstream.

Based on ANOVA and Duncan tests, the mean concentration of OCPs in water samples of the two points upstream and downstream showed no significant differences $(\mathrm{P}=0.05)$. 
Table 2: Mean concentration of organochlorine pesticides residues in immature and matured Catfish fish (mg/kg).

\begin{tabular}{lccccc}
\hline POPs & LOQ & immature fish & Mature fish & EU MRL & FEPA MRL \\
\hline Aldrin & 0.001 & trace & $0.027 \pm 0.023$ & 0.0001 & 0.01 \\
Endrin & 0.002 & $0.029 \pm 0.007$ & $0.038 \pm 0.012$ & 0.0001 & 0.01 \\
Dieldrin & 0.025 & $0.047 \pm 0.004$ & $0.087 \pm 0.032$ & 0.0001 & 0.01 \\
Heptachlor & 0.005 & $0.045 \pm 0.002$ & $0.051 \pm 0.001$ & 0.0001 & 0.01 \\
Lindane & 0.027 & $0.041 \pm 0.003$ & $0.047 \pm 0.002$ & 0.0001 & 0.01
\end{tabular}

The results of the average mean concentration of OCPs in immature and mature catfish are presented in Table 2. The result of the investigation showed that the mean concentration of the pesticide residues are found to be in the following range: aldrin was no detected in the immature catfish but have a value of $0.027 \pm 0.023 \mathrm{mg} / \mathrm{kg} \mathrm{in}$ mature catfish, Endrin $(0.029 \pm 0.007 \mathrm{mg} / \mathrm{kg})$ in immature catfish fish $(0.038 \pm 0.012 \mathrm{mg} / \mathrm{kg})$ in mature catfish, Dieldrin ranged from ( $0.047 \pm 0.004$ to $0.087 \pm 0.032)$; Heptachlor( $0.045 \pm 0.002$ to $0.051 \pm 0.001 \mathrm{mg} / \mathrm{kg}$ ); and lindane was found to be $(0.041 \pm 0.003$ to $0.047 \pm 0.002 \mathrm{mg} / \mathrm{kg})$ in immature and mature catfish respectively. The analysis revealed that the concentrations of all the OCPs investigated in the mature catfish were far higher than that present in the immature samples. Such high concentration is most significantly due to the bioaccumulation potentials of such chlorinated residues. The relatively higher concentration of dieldrin to aldrin is due to the fact that over time, aldrin is photolysed into dieldrin in plant or animal tissues (Afful et al., 2010). Significant differences were found in the mature and the immature catfish $(\mathrm{p}<0.05)$. Except for aldrin which is believed to have photolyed into dieldrin, all other OCPs analysed have their values high above the EU and FEPA MRLs which indicated that most of the fish in Lake Gariyo are contaminated with OCPs. Thus the catfish from such lake is considered a major source of POPs exposure to humans; because it accumulates in the fish tissue and sediment of the lake, and is immiscible in water (Dem et al., 2007). However, the values recorded in this study are higher than values reported by Shinggu et al., 2015, this shows there is an increase in the concentration of these pesticides in fish, due to the bioaccumulation potentials of such chlorinated residues.

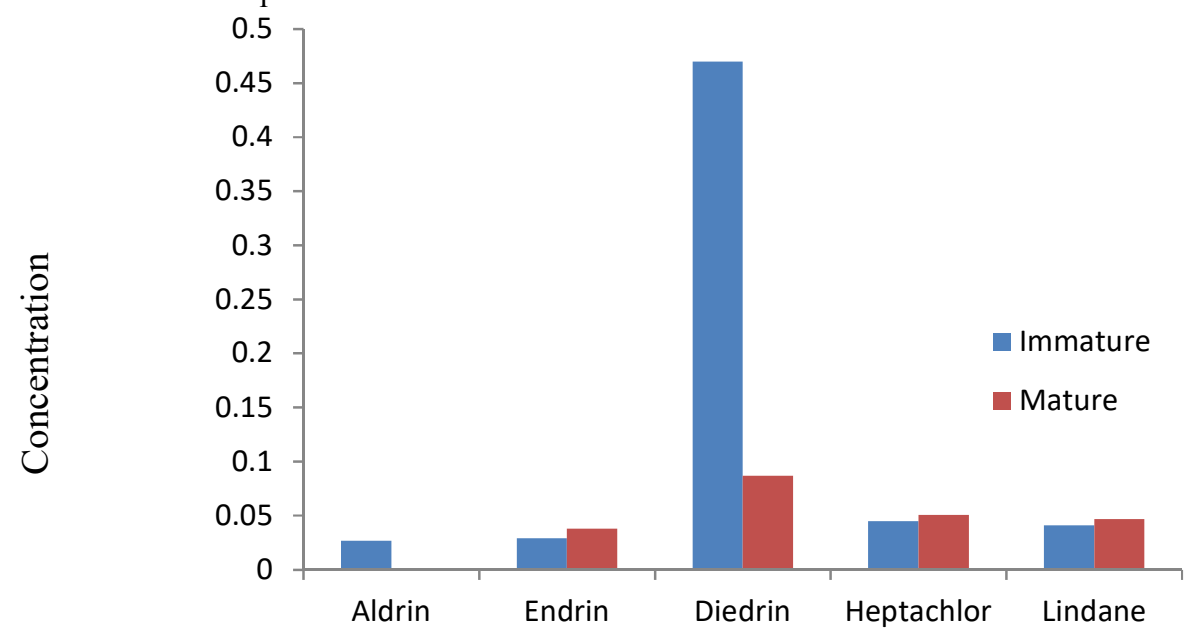

Figure 2: Comparison of OCPs between Immature and mature catfish

The figure 2 above shows that the most predominant OCPs in catfish is diedrin, which have a higher concentration in mature catfish.

Table 3: Mean concentrations of organochlorine pesticides residues in immature and mature Tilapia fish (mg/kg).

\begin{tabular}{|c|c|c|c|c|c|}
\hline POPs & LOQ & IMMATURE & MATURE & EU MRL & FEPA MRL \\
\hline Aldrin & 0.01 & traces & $0.021 \pm 0.002$ & 0.0001 & 0.01 \\
\hline Endrin & 0.002 & ND & $0.023 \pm 0.005$ & 0.0001 & 0.01 \\
\hline Dieldrin & 0.012 & $0.36 \pm 0.004$ & $0.57 \pm 0.003$ & 0.0001 & 0.01 \\
\hline Heptachlor & 0.015 & $0.36 \pm 0.004$ & $0.44 \pm 0.002$ & 0.0001 & 0.01 \\
\hline Lindane & 0.002 & $0.041 \pm 0.01$ & $0.067 \pm 0.007$ & 0.0001 & 0.01 \\
\hline
\end{tabular}

LOQ=Limit of quantification, $\mathrm{ND}=$ not detected, Traces $=$ Concentration below $\mathrm{LOQ}$ 
Table 3 above shows the mean concentrations of various chlorinated pesticides residues in Tilapia fish. The result revealed that aldrin and endrin were not detected in immature tilapia fish but were found to be $0.021 \mathrm{mg} / \mathrm{kg}$ to $0.023 \mathrm{mg} / \mathrm{kg}$ in the mature tilapia fish respectively. Dieldrin, Heptachlor and Lindane were all detected in both the mature and the immature tilapia fish, and all the values recorded of all the OCPs studied were higher than the recommended values by EU and FEPA MRL. The order of contamination of the studied OCPs in tilapia fish are in the order Dieldrin $>$ Heptachlor $>$ Lindane $>$ Aldrin $>$ Endrin.

With constant utilization of agrochemicals for agricultural or household purposes, coupled with its persistence and long range transport potentials, the environment is constantly plagued by these pollutants (Afful et al., 2010). Water bodies are major destinations for some of these chemical products, causing pollution and damages to aquatic life. Organochlorines have an affinity for particulate matter, and low solubility in water (Swati et al., 2015). These may explain their low prevalence in the water samples but higher concentrations in fish samples. This study showed that Dieldrin, Heptachlor and Lindane are the most predominant compounds among the organochlorines. Dieldrin is a chlorinated cyclodiene that was widely used in Nigeria. The National Agency for Food and Drug Administration and Control (NAFDAC) has banned the sale and supply of 30 different agrochemical products in the country which include aldrin and dieldrin in 2008 , because the toxicity of these persistent pesticides posed an imminent danger to human health. However, these products are still in used because of their low cost and affordability. The relatively higher amounts of dieldrin and high heptachlor prevalence may be due to its relatively low degradation and also due to high environmental usage (Akinnawo, 2016).

The fact that organochlorines are hydrophobic and lipophilic explains why higher concentrations were found in the fishes compared to the water course itself (Akan and Unylmadu, 2013). Since concentration of OCPs residues in fishes is based upon fat content, higher concentration was encountered for the catfish having a total fat content of about $13 \mathrm{~g}$, which is far more than that of Tilapia fish having a fat content of only $2.5 \mathrm{~g}$. Due to the synergistic mode of POPs interaction, even samples which gave concentrations within safe limits may constitute a great danger to consumers. For this reason, consumers of water or fishes from the lake Geriyo are at high risk of organochlorine toxicity (Ize-lyamu et al., 2007).



Figure 3: Comparison of organochlorine pesticides between Immature and mature Tilapia Fish.

The figure 3 indicated that the most predominant pesticides in tilapia fish are diedrin and heptachlor, with higher concentrations in mature tilapia fish. This study revealed that mature fish are more contaminated with OCPs than immature fish

The comparison of our results in water and fish revealed higher concentrations of these pesticides in fish than in water. The low levels of pesticide residues found in the water bodies than in the fish might be attributed to the fact that the input of pesticides in water is a function of suspended particulate concentrations, where the residues were absorbed and transported, as also commented by ( Bishnu et al.,2009), varied from season to season, depending on the rainfall events that control the activities of soil erosion and the amounts of suspended particulates, during runoff. The higher levels of pesticides found in the fish might be due to the fact that fishes have a greater tendency to accumulate the pesticides in their body due to bioaccumulation (Wan et al., 2005).

\section{Conclusion}

This study clearly outlined that both the water and fish samples from Lake Geriyo might be contaminated with the investigated chlorinated pesticides residues. Their concentrations especially dieldrin, lindane and heptachlor were 
consistently above the set MRLs values, such high concentrations may be due to their high persistent or continual usage despite legal restrictions.

The occurrence of the Organochlorine pesticides in fish and water from Lake Geriyo might be, due to many environmental factors such as leaching, water runoff, indiscriminate agricultural activities of that area and industrial waste products that flows from drainages into the Lake. However, pesticides contamination has many negative impacts on the ecosystem as well as on the health of the populace and the environment at large. This present study shows that the water and fish from Lake Geriyo might be slightly contaminated with OPCs; therefore there is need for regular or continuous monitoring of Lake Geriyo for organochlorine pesticides level in water and fish in order to adequately assess the water quality and, to ensure safe consumption by populace, also to prevent future environmental pollution as a result of organochlorine pesticide contamination of the water and fish of the lake. These pesticides are also more predominant in mature fish than the immature fish.

Based on the findings of this research, it is recommended that proper public sensitization on the hazards associated with the use of pesticides should be done regularly and more studies should be conducted on the source identification of these pesticides residues reported in samples from the study area. Moreover, periodic assessment of water and fishes in the study area should be done in order to ascertain their safety for consumption.

\section{References}

Adeyemi, D., Ukpo, G., Anyakora, C., Unyimadu, J.P., (2008). Organochlorine pesticide residues in fish samples from Lagos Lagoon, Nigeria. Am. J. Environ. Sci. 4 (6),649-653.

Afful, S., Anim, A.K., Serfor-Armah, Y., (2010). Spectrum of organochlorine pesticide residues in fish samples from the Densu Basin. Res. J. Environ. Earth Sci. 2 (3),133-138.

Akan B. Williams and John P. Unyimadu (2013). Organochlorine Pesticide Residues in Muscle Tissues of Ethmalosa Fimbriata and Psettias Sebae from Lagos Lagoon, Nigeria

Akinnawo Solomon (2016). Determination of Organochlorine Pesticide Residues in Water and Sediment Samples from Selected Areas of River Ilaje, Nigeria. American Chemical Science Journal 11(2): 1-6, 2016.

Bishnu A, Chakrabarti K, Chakraborty A, Saha T (2009). Pesticide residue level in tea ecosystems of Hill and Dooars regions of west Bengal, India. Environmental Monitoring and Assessment 2009; 149:457-464.

Darko, G., O. Akoto and C. Oppong, 2008. Persistent organochlorine pesticide residues in fish, sediment and water from lake Bosomtwi, Ghana. Chemo., 72(1): 21-24.

Dem, S.B., J.M. Cobb and D.E. Mullins, 2007. Pesticide residues in soil and water from four cotton growing areas of Mali, West Africa. J. Food Environ. Sci., 1: 1-12.

El-Mekkawi, H., Diab, M., Zaki, M., Hassan, A., 2009. Determination of chlorinated organic pesticide residues in water, sediments and fish from private fish farms at Abbassa and Sahl Al-Husainia Sharkia Governorate. Aus. J. Basic Appl. Sci. 3(4): 4376-4383.

Farshid Kafilzadeh, Amir Houshang Shiva, Rokhsareh Malekpour and Hamid Noorani Azad (2012). Determination of Organochlorine Pesticide Residues in Water, Sediments and Fish from Lake Parishan, Iran. World Journal of Fish and Marine Sciences 4 (2): 150-154, 2012

Guo, Y.,Meng, X.Z., Tang, H.L., Zeng, E.Y., 2008. Tissue distribution of organochlorine pesticides in fish collected from the Pearl River delta, China: implications for fishery input source and bioaccumulation. Environ. Pollut. 155 (1), 150-156.

Imo, S.T., Sheikh, M.A., Hirosawa, E., Oomori, T., Tamaki, F., 2007.Contamination by organochlorine pesticides from rivers. Int. J. Environ. Sci. Technol. 4 (1), 1-9.Int. J. Aqua; (IA): 179-202.

Ize-Iyamu, OK., I.O. Asia and P.A. Egwakhide, 2007. Concentrations of residues from organochlorine pesticide in water and fish from some rivers in Edo State Nigeria. Int. J.Phys. Sci., 2: 237-241.

Shinggu, D. Y, Maitera O.N, and Barminas J. T (2015). Determination of organochlorine pesticides Residue in Fish, water and Sediment in lake Geriyo, Adamawa State. International Journal of Pure and Applied Chemistry.8 (4): 212-220.

Swati Singh, Dawa Bhutia, Sanjib Sarkar, Benoy Kishore Rai, Joydeb Pal, Soumen Bhattacharjee, Min Bahadur (2015). Analyses of pesticide residues in water, sediment and fish tissue from river Deomoni flowing through the tea gardens of Terai Region of West Bengal, India. International Journal of Fisheries and Aquatic Studies 2015; 3(2): 17-23

US Environmental Protection Agency (USEPA). Method 3510, Revision C Washington DC: USEPA; 2007.

Wang, T., Khim, J. S., Luo, W., Jiao, W., Lu, Y., Laile, J. E., Chen, C., Zhang, X., Giesy, J.P., (2010). HCH and DDT in sediments from marine and adjacent Riverine areas of north Bohai Sea, China.Arch.Environ. Conta. Toxicol.,doi:10/1007/a00244-009-9455-z.

Wan MT, Kuo J, Pasternal J. (2005). Residues of endosulfan and other selected organochlorine pesticides in farm areas of the lower Fraser Valley, British Columbia, Canada. Journal of Environmental Quality. 2005; 34:1186-1193. 